photograph was taken August 1i, about eighty-two hours after the injury. There was only a little sloughing at the point of injection of the poison, but the man was incapacitated for work about thirty days. As to treatment, the arm was corded tightly, an abundance of whisky was given, and hypodermic injections of strychnin $1 / 40 \mathrm{~g}$. ever forty-five minutes. He has gone to work and has a good arm.

\section{FATAL CASE OF BLACKWATER FEVER SUPER- VENING ON AMEBIC DYSENTERY AND SHOWING MALARIAL PARASITES IN THE BLOOD.*}

\section{F. CREIGHTON WELLMAN, M.D. BENGUELLA, WEST AFRICA.}

Patient.-Lieutenant M. de G., aged 26, Portuguese, was first seen Dec. 20, 1904.

History.-The patient had been in Africa two years. The first year and a half of this time were spent on the coast, the last six months in the interior. He has never suffered much from malaria nor blackwater fever. Recently he was again sent to the coast, where he spent three weeks. As he was leaving to return to the interior he was attacked with a sharp diarrhea and passed some blood. He recovered in a few days and continued his journey. He has had some looseness of the bowels, with occasional pains, ever since. After his arrival at Bihi fort he had a relapse of the "diarrhea" and was in considerable distress and very weak. He thought he also had some fever, so he came to me for advice.

General Condition.-The patient was thin, weak and feverish. He had no appetite. His tongue was foul. Temperature was $102.4 \mathrm{~F}$., pulse 93 , respiration 28 . The spleen was slightly enlarged. There was tenderness over the lower bowels. The other organs were normal. At stool there was moderate tenesmus. He had taken no medicine except a diarrhea mixture, ingredients unknown. He considered this the second day of his disease (relapse).

Examination of Feces.-The stools were small and unformed, consisting almost entirely of blood and mucus. There was one moderate-sized slough. Under the mieroseope many amebremorphologically identical with Amaba coli (Lösch) were seen.

Examination of Blood.-Both fresh and stained specimens were examined, one of each. In the latter two malarial parasiles were seer; both were small intracapsular forms. The result of a differential lencoeyte count was as follows (about 50 cells counted) :

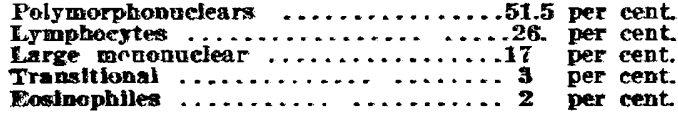

Transitional $\ldots \ldots \ldots \ldots \ldots \ldots \ldots \ldots \ldots \ldots \ldots \ldots \ldots$ z per cent.

The initial and succeding erythroeyte counts are shown in the chart.

Examination of Urine.-The urine was dark but clear. The spectroscope revealed none of the compounds of hemoglobin. There was a trace of albumin.

Course of the Disease. - The patient was plaeed in bed (11 a. m.), and small doses of Epsom salts in solution every hour were prescribed. He was placed on liquid diet with a little brandy. In spite of frequent sponging of the body the temperature steadily rose until 5 p. m., when the hemoglobinuria set, in.

Re-examination of Urine--After the hemoglobinuria set in, the urine was re-examined; the color was about like that of porter or stout. There was a dirty-gray sediment, showing unter the microscope débris, masses of hemoglobin, and some hyraline and granular casts. The urine was not spectroscoped at first. In later specimens the bands of both oxyhemogrobin and reduced hemoglobin could be seen by shaking up the urine, examining it, adding ammonium sulphid and exam. ining again.

- Published under the auspices of the American Soclety of Tropical Medicine.
Further Course of the Disease.-Amceba coli persisted in the stools (which showed some improvement) throughout the attack, but malarial parasites were not demonstrated in three successive blood examinations. On the morning of the sixth day of the disease the temperature was found to have spontaneously fallen to $101 \mathrm{~F}$. The following day severe hiccoughs set in which nothing availed to control. The patient died at $4: 20 \mathrm{p}$. m. on the twelfth day.

Treatment.-The treatment pursued was entirely symptomatic and expectant. The saline routine for the dysentery, liquid nourishment and stimulants were administered for the weakness and the usual ineffectual gamut of sedatives and other devices were tried to control the hiccoughs. Quinin was not administered at any period of the attack as hemoglobinuria was feared from the first.

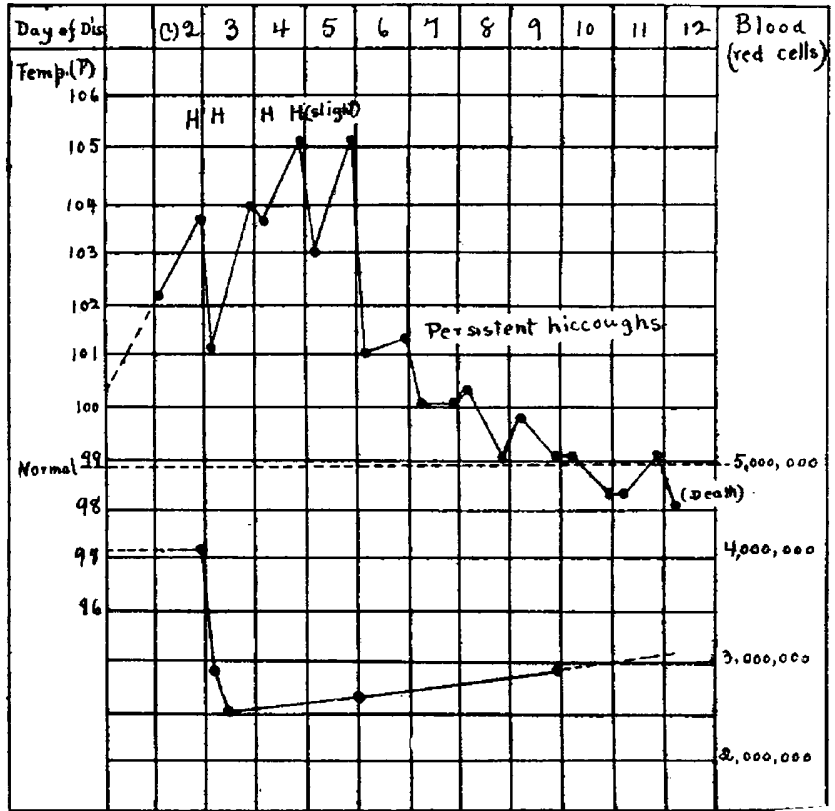

Chart 1.-The blood counts were made on the Thoma-Zeiss hemocytometer. In the first two counts, the blood was also centrifuged and the reading on the hematocrit compared with the result of the actual count. $H=$ hemoglobinuria.

\section{REMARKS.}

1. This is the thirty-fourth case which I have studied more or less carefully in West Africa. Of this series 29 patients recovered.

2. The case just recorded is the only instance in which death occurred during the first attack. This may be explained by the previous and synchronous dysentery.

3. In three cases malarial parasites were seen in the blood immediately preceding the hemoglobinuria. In the present case the return of the dysentery probably brought about an explosion of latent malaria, and the two conditions combined were able to produce the physiologic depression and hypotonicity of the blood that invited the intercurrent hemoglobinuria.

4. The question of the relation between malaria and blackwater fever is of great interest, but too intricate to be discussed in a paper of this kind. I believe that they are related in some way, and I have shown that in southern Angola the geographical distribution of Myzomyia funesta, Giles (the principal carrier of $H$. pracox in West Africa), severe malaria and hemoglobinuric fever closely coincide. The precise character of the relation between the two diseases (which is disputed by some) has not yet been shown. 